Review

\title{
Application of Chromatographic and Electrophoretic Methods for the Analysis of Imidazolium and Pyridinium Cations as Used in Ionic Liquids
}

\author{
P. Stepnowski \\ Faculty of Chemistry, University of Gdańsk, Sobieskiego 18, PL-80-952 Gdańsk, Poland; \\ E-Mail: sox@chem.univ.gda.pl; Tel. (+48 58) 345 0448; Fax. (+48 58) 3450454 \\ Received: 30 August 2006 / Accepted: 16 November 2006 / Published: 17 November 2006
}

\begin{abstract}
Interest in ionic liquids for their potential in different chemical processes is constantly increasing, as they are claimed to be environmentally benign - excellent, nonvolatile solvents for a wide range of applications. The wide applicability of these compounds also demands reliable, relatively simple and reproducible analytical techniques. These methods must be applicable not only to different technical or natural matrices but also to the very low concentrations that are likely to be present in biological and environmental systems. In this review, therefore, methods for separating and analysing imidazolium- and pyridinium-type ionic liquids in aqueous matrices using high performance liquid chromatography (HPLC) and capillary electrophoresis (CE) are examined. The techniques for identifying ionic liquids are meant primarily to track the concentrations of ionic liquids as residues not only in products and wastes but also in biological or environmental samples. The application of hyphenated techniques in this field is intended to selectively separate the quaternary entity from other cationic and non-ionic species present in the matrix, and to enable its fine-scale quantification. Nowadays, methods developed for cation analysis are based mostly on reversed-phase high-performance liquid chromatography, ion chromatography, ion-pair chromatography and capillary electrophoresis, where various buffered mobile phases are used.
\end{abstract}

Keywords: ionic liquids, imidazolium salts, pyridinium salts, analysis, separation, HPLC, CE 


\section{Introduction}

Room temperature ionic liquids (RTIL) are a novel, broad class of semi-organic salts or salt mixtures that are liquid below $100^{\circ} \mathrm{C}$. Apart from their negligible vapour pressure, believed to be the main 'green' feature of ionic liquids, one of their most attractive characteristics is the potential to be 'designed to order'. Properties such as density, moisture stability, viscosity or miscibility with other solvents can be tailored by the appropriate selection of cation and anion; a very rough estimate indicates that such combinations can be numbered in the millions. RTIL already in common use typically involve nitrogen- or phosphorus-containing organic cations such as alkylimidazolium, alkylpyridinium, alkylpyrrolidinium or alkylphosphonium, and anions like bis(trifluoromethanesulphonyl)imide, hexafluorophosphate or tetrafluorophosphate [1-5]. Although these particular cations and anions and their various combinations have already been studied extensively for their potential applications in numerous chemical and physical processes, every year more and more cations and anions forming liquid salts at room temperature are reported.

Table 1 present the generic structures of typical ionic liquids. Two general parameters determine the properties of alkylimidazolium ionic liquids. One is the choice of anion, which above all determines water miscibility, and which in turn can have further dramatic effects on the liquid's properties. The other is the length of the alkyl chain in the cation: lengthening this from butyl to hexyl or octyl increases the hydrophobicity and viscosity of ionic liquids, but decreases their density and surface tension [5]. Table 2 sets out selected physical properties of two alkylimidazolium cations combined with different anions.

Table 1. Common examples of ionic liquids

\begin{tabular}{lc|l}
\hline Ionic liquid type & Structure & Ionic liquid type \\
\hline Alkylammonium & Structure \\
Alkylphosphonium &
\end{tabular}

$\mathrm{X}^{-}: \mathrm{BF}_{4}^{-}, \mathrm{PF}_{6}^{-}, \mathrm{AlCl}_{4}^{-}, \mathrm{SbF}_{6}^{-}, \mathrm{CF}_{3} \mathrm{SO}_{3}^{-},\left(\mathrm{CF}_{3} \mathrm{SO}_{2}\right)_{2} \mathrm{~N}^{-}$etc. $\quad \mathrm{R}_{x}$ : from $-\mathrm{CH}_{3}$ to $-\mathrm{C}_{9} \mathrm{H}_{19}$

Current research indicates that replacing an organic solvent with an RTIL can bring about remarkable improvements in well-known processes. Ionic liquids have been applied not only as alternative solvents in organic synthesis and catalysis, and as electrolytes in batteries and solar cells, but also in liquid-liquid extraction, as components of gas chromatography stationary phases, as running 
electrolytes in capillary electrophoresis, as mobile-phase additives in HPLC, and in embalming and tissue preservation [6-11].

Table 2. Selected properties of 1-butyl- and 1-hexyl-3-methylimidazolium chlorides, tetrafluoroborates and hexafluorophosphates

\begin{tabular}{ccccccc}
\hline Ionic liquid & $\begin{array}{c}\text { MP } \\
{\left[{ }^{\circ} \mathrm{C}\right]}\end{array}$ & $\begin{array}{c}\text { Density } \\
{\left[\mathrm{g} \mathrm{ml}^{-1}\right]}\end{array}$ & $\begin{array}{c}\text { Viscosity } \\
{[\mathrm{cP}]}\end{array}$ & $\begin{array}{c}\text { Water } \\
\text { Solubility }\end{array}$ & $\begin{array}{c}\text { Temp. limit } \\
{\left[{ }^{\circ} \mathrm{C}\right]}\end{array}$ & Reference \\
\hline$[\mathrm{BMIM}][\mathrm{Cl}]$ & 41 & 1.08 & 716 & $\mathrm{~S}$ & 254 & {$[5]$} \\
{$[\mathrm{BMIM}]\left[\mathrm{BF}_{4}\right]$} & -81 & 1.12 & 219 & $\mathrm{~S}$ & 360 & {$[5],[33]$} \\
{$[\mathrm{BMIM}]\left[\mathrm{PF}_{6}\right]$} & 10 & 1.37 & 371 & $\mathrm{NS}$ & 349 & {$[5],[33],[34]$} \\
{$[\mathrm{HMIM}][\mathrm{Cl}]$} & -70 & 1.03 & - & $\mathrm{S}$ & 253 & {$[5],[36]$} \\
{$[\mathrm{HMIM}]\left[\mathrm{BF}_{4}\right]$} & -82 & 1.21 & 314 & $\mathrm{PS}$ & - & {$[5]$} \\
{$[\mathrm{HMIM}]\left[\mathrm{PF}_{6}\right]$} & -61 & 1.30 & 582 & $\mathrm{NS}$ & 376 & {$[5],[35],[36]$} \\
\hline
\end{tabular}

S- soluble, PS - partly soluble, NS - non soluble

The wide applicability of ionic liquids as well as advances in the variety of applications will soon result in their production and use on an industrial scale. Since it has already been found that even small amounts of impurities significantly affect the performance of ionic liquids, analytical methods determining their purity will be very much in demand. In addition, research of considerable practical importance, such as investigations of the toxicity, ecotoxicity and persistency of RTIL in the environment, will also require reliable, relatively simple and reproducible analytical techniques. These methods must not only be applicable to different natural matrices but also to the very low concentrations likely to be present in biological and environmental systems. Finally, ionic liquids are nowadays one of the leading examples of Green Chemistry, the $11^{\text {th }}$ principle of which states that for every newly designed and produced chemical 'analytical methodologies need to be developed to allow for real-time, in-process monitoring and control prior to the formation of hazardous substances' [12].

Nowadays, there are two general approaches to the analysis of ionic liquids: one identifies ionic liquids as analytes in natural or artificial matrices, the other assesses their purity. Reported techniques for identifying ionic liquids have above all been designed to track their concentrations, not only as residues in products and wastes but also in biological or environmental samples. So far this has been done mainly via cation analysis, since it has been found, especially in biological and environmental experiments, that varying the anion affects the distribution and activity of imidazolium and pyridinium ionic liquids to only a slight extent. Hyphenated techniques in this field are intended to selectively separate the quaternary entity from other cationic and non-ionic species present in the matrix and to enable its fine-scale quantification. Present-day methods of cation analysis are based primarily on 
reversed-phase high-performance liquid chromatography, ion chromatography, ion-pair chromatography, and capillary electrophoresis, in which various buffered mobile phases are used.

The purity assessment of ionic liquids is a subject of major technological importance. Many studies have shown that even small amounts of impurities can significantly affect the performance of an ionic liquid [5, 13]. The principal research effort in this field is currently being directed towards the quantification of anionic impurities in ionic liquids. This is largely the upshot of the limited catalytic performance of ionic liquids contaminated with small amounts of residual chlorides, originating from the starting substrates in ionic liquid syntheses [14-15]. Residual halides may also affect other physicochemical properties of ionic liquids, such as viscosity, density or spectral purity. In this area of development, it is methods based on ion chromatography, capillary electrophoresis and ion-coupled plasma mass spectrometry that are mainly reported in the literature [16-19].

The primary aim of this review is to outline current developments in chromatographic and electrophoretic methods for separating and analysing the cations commonly used in ionic liquids. Although the presence of anions and their influence on separation processes is also discussed, the analysis of anionic impurities is not reviewed here.

\section{Molecular interaction potential of ionic liquids}

The analysis of the molecular interaction potential of ionic liquids is a very useful tool for acquiring a fuller understanding of their behaviour in various separation systems. The present section addresses this question using the most common alkylimidazolium entity as an example. On entering an aqueous matrix, cations and anions dissociate, and depending on the presence of other ions, they will either act as free species or associate into new ion pairs. In the case of most currently used ionic liquid anions, the main interaction mechanism is electrostatic. However, where alkylimidazolium cations are concerned, far more complex interactions with the mobile- and stationary phases may take place during separation. The high electron acceptor potential of delocalised aromatic systems in the cationic compartments of ionic liquids is responsible for electrostatic attractions not only with ionised weak (e.g. carboxylic) or strong (e.g. sulphonate) cation exchangers, but also with polar moieties on particle surfaces, such as free silanols. It is also clear that elongating the alkyl chain of ionic liquids elevates the molecule's hydrophobicity. It is therefore also possible that ionic liquid cations with longer alkyl moieties are retained in reversed phase systems by hydrophobic interactions. This can occur between the ionic liquid's alkyl chain and the alkyl moiety of the stationary phase, as well as other alkyl chains of ionic liquid cations previously bound to the stationary surface. This mechanism, moreover, is strongly dependent on the anions present in the system, with which selected cations form ion-pairs, thereby enabling the molecule to be partitioned. Finally, the aromatic system within an imidazolium ring offers $\pi$... $\pi$ interaction potential with any aromatic moieties in $\pi$-electron-rich stationary phases (e.g. polar RP) and solvents (e.g. acetonitrile). 


\section{Chromatographic methods}

\subsection{Reversed phase chromatography}

Most of the methods for separating and determining ionic liquid cations reported so far involve high-performance liquid chromatography (HPLC) with a variety of column packings and mobile phases. Table 3 summarises published protocols developed for ionic liquid cation separation and analysis.

The separation and analysis of eleven imidazolium ionic liquids congeners was first studied systematically using reversed-phase HPLC with electrospray ionisation mass detection [20]. With the use of a buffered mobile phase (20mM ammonium acetate/acetic acid), it was found that different anions in these ionic liquids did not affect the chromatographic behaviour of the same cation. This was confirmed by comparing the retention values of dissociated pairs: [BMIM][Br] with [BMIM] $\left[\mathrm{BF}_{4}\right]$, [AMIM] $[\mathrm{Cl}]$ with $[\mathrm{AMIM}]\left[\mathrm{PF}_{6}\right]$, and $[\mathrm{HpMIM}][\mathrm{Cl}]$ with $[\mathrm{HpMIM}]\left[\mathrm{PF}_{6}\right]$. It was also found that analysis of ionic liquid cations on a conventional reversed phase column with a low surface coverage of ligands led to very poor separations and a low reproducibility of retention values. This was due mainly to the continued presence of free silanols in the stationary phase, observed as marked peak tailing of all these analytes. Further development of this method therefore involved the evaluation of alternative reversed phase packings; a much-improved performance was achieved using an RP-8 column with a higher carbon load. Using such a column, the authors were able to efficiently separate and quantify a mixture of alkyl- and aryl-substituted imidazolium entities, even though the resolution was still unsatisfactory in the range of early eluting compounds (short chain ionic liquids). Gradient separation of the test mixture was further developed to optimise elution times for late eluting entities. With a mobile phase consisting of acetonitrile : water ( $1 \%$ acetic acid/20mM ammonium acetate), in which the organic modifier concentration was raised from 10 to $50 \%$ in 25 min., the most hydrophobic ionic liquid cation used in this study (1-heptyl-3-methylimidazolium chloride) eluted after 23 min. Further, in order to validate the method's applicability, a sample of cell-growing medium used in cytotoxicity studies of a known micromolar concentration of the ionic liquid $[\mathrm{AMIM}]\left[\mathrm{PF}_{6}\right]$ was tested. The compound was well isolated, identified and quantified with very good analytical performance parameters.

The chromatographic behaviour of 1-alkyl-3-methylimidazolium ionic liquid cations in the reversed phase system with buffered mobile phases was further studied in detail [21]. All the ionic liquids analysed in this particular paper exhibited reversed-phase behaviour on being separated. When the methanol concentration in the mobile phase was increased, the retention time of all the compounds decreased, although there were differences in the retention profiles depending on the type of $N-1$ functional group on the imidazolium ring. All 1-methyl-3-alkylated species displayed quite similar behaviour within the range of organic modifier used, exhibiting comparable slopes $S$ of the classical Soczewiński-Snyder model $\left(\log k=\log k_{w}-S \phi\right)$ of -0.032 . The retention factors, and hence the $S$ value of the less hydrophobic 1-ethyl-3-ethylimidazolium, were modified only at the lowest methanol concentrations; above $20 \%$ (v/v) it was eluted within the dead time of the system. The decreasing polarity of the mobile phase up to $30 \%(\mathrm{v} / \mathrm{v})$ methanol merely modified the intensity of interaction between solutes and the stationary phase. It was confirmed that selective separation of highly hydrophilic solutes such as $[\mathrm{BMIM}]^{+}$or $[\mathrm{EEIM}]^{+}$cations in one isocratic run with more hydrophobic ionic liquids is therefore practically impossible. Variation of either the $\mathrm{pH}$ or the salt concentration in the mobile phase did not significantly affect the retention factors of the ionic liquids. A detailed study of the reversed phase liquid chromatography of alkyl-imidazolium ionic liquids was recently reported [22]. The authors found that while using buffer-free mobile phase systems, anions influenced the 
retention of the same ionic liquid cation. An aqueous mobile phase (with no buffer added) allows for additional interactions of anions with the RP stationary phase, but since they cannot move alone, they influence cation retention by forming ion pairs.

In another, related study it was found that anions were adsorbed on to RP phases in accordance with their lyotropic character [23]. In the chromatographic process, the affinity of ionic liquid ions for the C18 stationary phase was as follows: $[\mathrm{Cl}]^{-}$and $[\mathrm{Br}]^{-}$(no affinity) $[\mathrm{EMIM}]^{+}<\left[\mathrm{BF}_{4}\right]^{-}<[\mathrm{BMIM}]^{+}<\left[\mathrm{PF}_{6}\right]^{-}$ $<[\mathrm{HMIM}]^{+}<[\mathrm{OMIM}]^{+}$. The authors also found that on raising ionic liquid concentrations from 1 to $11 \mathrm{mM}$, peak shapes changed to the fronting type. This usually corresponds to the concave isotherm shape, also observed in separations of other ionisable compounds in the RP system. This type of retention is explained by the different affinities of the cation and anion compartments for the stationary phase. For example, the weakly lyotropic anion $\left[\mathrm{PF}_{6}\right]^{-}$and the hydrophobic cation $[\mathrm{HMIM}]^{+}$in $[\mathrm{HMIM}]\left[\mathrm{PF}_{6}\right]$ ionic liquid must move together, even though the $\left[\mathrm{PF}_{6}\right]^{-}$anion alone would elute faster [22].

\subsection{Ion chromatography}

Paper [24] is the first report on the use of ion chromatography to analyse 1-methyl-3ethylimidazolium and sodium cations in the buffered 1-methyl-3-ethylimidazolium chloride-aluminium chloride ionic liquid system. The analytical performance parameters were found to be very good; the calibration curve for the ionic liquid cation was linear over three orders of magnitude and the accuracy of the method was $\pm 2.8 \%$ relative error.

In a more recent study, the behaviour of eight ionic liquids - seven homologues of 1-alkyl-3methylimidazolium and 4-methyl-N-butylpyridinium - was investigated with a strong cation exchange adsorbent [21]. In particular, the dependences of the retention properties of these solutes on mobile phase composition, $\mathrm{pH}$ and buffer concentration were evaluated with the aim of optimising and improving the selectivity and retention of solute separation. With the SCX stationary phase, several interactions occurred with varying strength depending on the mobile phase composition. Reversed phase chromatography occurred at low concentrations of acetonitrile in the mobile phase, electrostatic and adsorption interactions at higher organic modifier concentrations. Elevated buffer concentrations reduced retention factors without affecting the selectivity of the alkylimidazolium cations. Appropriate modifications of the mobile phase enabled even the most hydrophilic cations to be separated and analysed; this is a challenge in RP separation. With 40-60\% acetonitrile in the mobile phase, separation of the hydrophobically similar 1-ethyl-3-ethylimidazolium and 1-butyl-3-methylimidazolium entities was successfully achieved. The analytical performance parameters were assessed under optimised chromatographic conditions with an acetonitrile - 30mM K $\mathrm{HPO}_{4}$ (40:60) mobile phase. 1-butyl-3methylimidazolium was chromatographed in the concentration range $1-100 \mu \mathrm{M}$. The correlation coefficient for the resultant calibration plots was 0.998 . The reproducibility of the peak area was $1.36 \%$ (RSD), and the reproducibility for peak retention was $0.23 \%$ (RSD). The detection limit established for the 1-butyl-3-methylimidazolium cation was $20 \mu \mathrm{g}$. The method is directly applicable to the analysis of ionic liquid cations in aqueous environmental or industrial samples. 
Table 3. Chromatographic and capillary electrophoretic methods used for separation and analysis of ionic liquids

\begin{tabular}{|c|c|c|c|c|}
\hline Ionic liquids analyzed* & Stationary phase & Mobile phase & $\mathrm{LOD}^{* *}$ & Ref. \\
\hline$[\mathrm{EMIM}]\left[\mathrm{AlCl}_{4}\right]$ & IonPac CS3 (Dionex) & $\begin{array}{l}25 \mathrm{mM} \mathrm{HCl}+0.35 \mathrm{mM} \\
\text { 2,3-diaminopropionic } \\
\text { acid }\end{array}$ & $10 \mathrm{ppm}$ & {$[24]$} \\
\hline $\begin{array}{l}{[\mathrm{EEIM}][\mathrm{Br}],[\mathrm{PMIM}][\mathrm{Br}],[\mathrm{PEIM}][\mathrm{Br}],} \\
{[\mathrm{BMIM}][\mathrm{Cl}],[\mathrm{BzMIM}]\left[\mathrm{BF}_{4}\right],[\mathrm{AMIM}][\mathrm{Cl}],} \\
{[\mathrm{EBzMIM}][\mathrm{Cl}],[\mathrm{pMBzM}][\mathrm{Cl}],} \\
{[\mathrm{HMIM}][\mathrm{Cl}],[\mathrm{HEIM}][\mathrm{Cl}],[\mathrm{HpMIM}][\mathrm{Cl}]}\end{array}$ & $\begin{array}{l}\text { MetaSil Basic } \mathrm{C}_{8} \\
\text { (Varian) }\end{array}$ & $\begin{array}{l}\text { acetonitrile : water }(1 \% \\
\text { acetic acid / } 20 \mathrm{mM} \\
\text { ammonium acetate })\end{array}$ & $1.6 \mathrm{ppm}$ & {$[20]$} \\
\hline $\begin{array}{l}{[\mathrm{EMIM}][\mathrm{Br}],[\mathrm{EMIM}]\left[\mathrm{BF}_{4}\right],[\mathrm{EMIM}]\left[\mathrm{PF}_{6}\right],} \\
[\mathrm{BMIM}] \mathrm{Cl}],[\mathrm{BMIM}]\left[\mathrm{BF}_{4}\right],[\mathrm{BMIM}]\left[\mathrm{PF}_{6}\right], \\
[\mathrm{HMIM}] \mathrm{Cl}],[\mathrm{HMIM}]\left[\mathrm{BF}_{4}\right],[\mathrm{HMIM}]\left[\mathrm{PF}_{6}\right] \\
[\mathrm{OMIM}] \mathrm{Cl}],[\mathrm{OMIM}]\left[\mathrm{BF}_{4}\right],\left[\mathrm{OMIM}^{-}\left[\mathrm{PF}_{6}\right]\right.\end{array}$ & $\begin{array}{l}\text { Kromasil C-18 (Eka } \\
\text { Azko Nobel) }\end{array}$ & $\begin{array}{l}\text { acetonitrile : water } \\
\text { (unbuffered) }\end{array}$ & - & {$[22]$} \\
\hline 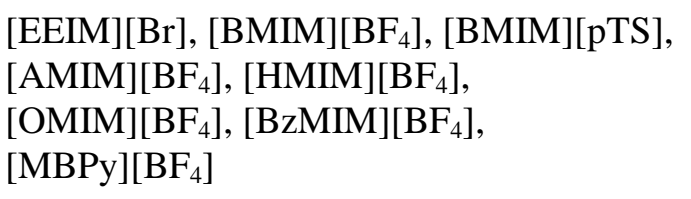 & MetaSil SCX (Varian) & $\begin{array}{l}\text { acetonitrile : water } \\
\left(30 \mathrm{mM} \mathrm{K}_{2} \mathrm{HPO}_{4}\right)\end{array}$ & $1.4 \mathrm{ppm}$ & {$[21]$} \\
\hline $\begin{array}{l}{[\mathrm{EMIM}][\mathrm{Cl}],[\mathrm{EEIM}][\mathrm{Cl}],[\mathrm{PMIM}][\mathrm{Cl}],} \\
{[\mathrm{BMIM}][\mathrm{Cl}],[\mathrm{HMIM}][\mathrm{Cl}],[\mathrm{OMIM}][\mathrm{Cl}]} \\
{[\mathrm{NMIM}][\mathrm{Cl}],[\mathrm{BzMIM}][\mathrm{Cl}],[\mathrm{EBzMIM}][\mathrm{Cl}],} \\
{[\mathrm{MBPy}][\mathrm{Cl}]}\end{array}$ & $\begin{array}{l}\text { Synergi Polar-RP } \\
\text { (Phenomenex) }\end{array}$ & $\begin{array}{l}\text { methanol or acetonitrile } \\
\text { : water }\left(5 \mathrm{mM} \mathrm{KH}_{2} \mathrm{PO}_{4} /\right. \\
\left.\mathrm{H}_{3} \mathrm{PO}_{4}\right)\end{array}$ & $0.1 \mathrm{ppm}$ & {$[25]$} \\
\hline $\begin{array}{l}{[\mathrm{PMIM}]\left[\mathrm{BF}_{4}\right],[\mathrm{BMIM}]\left[\mathrm{BF}_{4}\right],[\mathrm{AMIM}]\left[\mathrm{BF}_{4}\right],} \\
{[\mathrm{HMIM}]\left[\mathrm{BF}_{4}\right]}\end{array}$ & $\begin{array}{l}\text { Immobilized artificial } \\
\text { membrane (Regis) }\end{array}$ & $\begin{array}{l}\text { methanol : water } \\
\left(20 \mathrm{mM} \mathrm{K}_{2} \mathrm{HPO}_{4}\right)\end{array}$ & - & {$[27]$} \\
\hline \multirow[t]{3}{*}{$\begin{array}{l}{[\mathrm{PMIM}]\left[\mathrm{BF}_{4}\right],[\mathrm{BMIM}]\left[\mathrm{BF}_{4}\right],[\mathrm{AMIM}]\left[\mathrm{BF}_{4}\right]} \\
{[\mathrm{HMIM}]\left[\mathrm{BF}_{4}\right],[\mathrm{BEIM}]\left[\mathrm{BF}_{4}\right]} \\
{[\mathrm{pMBzMIM}]\left[\mathrm{BF}_{4}\right],[\mathrm{MBPy}]\left[\mathrm{BF}_{4}\right]}\end{array}$} & $\begin{array}{l}\text { RP-18e Purospher }{ }^{\mathrm{TM}} \text { Star } \\
\text { and Innovation } \\
\text { Chromolith }^{\mathrm{TM}} \text { (Merck), }\end{array}$ & $\begin{array}{l}\text { methanol : water }(40 \\
\left.\text { mM KH}{ }_{2} \mathrm{PO}_{4}\right)\end{array}$ & - & [26] \\
\hline & $\begin{array}{l}\text { Macrosphere } 300 \mathrm{C} 8 \text { and } \\
\text { C4 (Alltech) }\end{array}$ & & & \\
\hline & $\begin{array}{l}\text { SG-alkylamide, SG- } \\
\text { choleste-rolic, SG-mixed, } \\
\text { SG-phenyl and SG-aryl } \\
\text { (Home-made columns) }\end{array}$ & & & \\
\hline $\begin{array}{l}\text { Imidazole, 1-methylimidazole, 1,2- } \\
\text { dimethylimidazole, [EMIM][Cl], [BMIM][Cl], } \\
{[\text { iBMIM }][\mathrm{Br}]}\end{array}$ & $\begin{array}{l}\text { Bare fused silica } \\
\text { capillary (Polymicro } \\
\text { Technologies) }\end{array}$ & $\begin{array}{l}\text { triethylammonium acetate } \\
(5 \mathrm{mM}, \mathrm{pH} 4.5,2.0 \mathrm{mM} \alpha- \\
\mathrm{CD})\end{array}$ & $0.4 \mathrm{ppm}$ & {$[31]$} \\
\hline $\begin{array}{l}\text { [MMIM] }[\mathrm{Br}],[\mathrm{EMIM}][\mathrm{Br}],[\mathrm{EEIM}][\mathrm{Br}], \\
{[\mathrm{PMIM}][\mathrm{Cl}],[\mathrm{BMIM}]\left[\mathrm{BF}_{4}\right],[\mathrm{HMIM}]\left[\mathrm{BF}_{4}\right],} \\
{[\mathrm{OMIM}]\left[\mathrm{BF}_{4}\right],[\mathrm{NMIM}]\left[\mathrm{BF}_{4}\right],[\mathrm{DMIM}][\mathrm{Cl}],} \\
{\left[\mathrm{BzMIM}^{-} \mathrm{BF}_{4}\right],[\mathrm{pMBzMIM}][\mathrm{Cl}]}\end{array}$ & $\begin{array}{l}\text { Bare fused silica } \\
\text { capillary (Polymicro } \\
\text { Technologies) }\end{array}$ & $\begin{array}{l}\text { citric buffer }(200 \mathrm{mM} \\
\mathrm{pH} 4.0)\end{array}$ & $0.1 \mathrm{ppm}$ & {$[32]$} \\
\hline
\end{tabular}

**[EEIM] 1-ethyl-, [PEIM] 1-propyl- [HEIM] 1-hexyl-3-ethylimidazolium

[PMIM] 1-propyl-, [BMIM] 1-butyl-, [AMIM] 1-amyl-, [HMIM] 1-hexyl-, [HpMIM] 1-heptyl-, [OMIM] 1-octyl-, [NMIM] 1-nonyl-3-methylimidazolium,

[BzMIM] 1-benzyl-, [EBzMIM] 1-(2-phenylethyl)-, [pMBzMIM] 1-p-methylbenzyl-3-methylimidazolium,

[MBPy] $N$-butylmethylpyridinium, $[\mathrm{Cl}]$ chloride, $\left[\left[\mathrm{BF}_{4}\right]\right.$ tetrafluroborate, $[\mathrm{pTs}]$ tosylate, $[\mathrm{Br}]$ bromide

**LOD - Limit of detection 


\subsection{Polar-reversed phase chromatography}

The aromatic system in the imidazolium ring of an ionic liquid cation offers potential $\pi \ldots \pi$ interaction with any aromatic moieties available in the phase. The possible usefulness of $\pi$... $\pi$ interactions in the selective separation of imidazolium and pyridinium ionic liquid cations is reported in [25]. In this study special attention was paid to short-chain hydrophilic entities, known to be poorly separated on conventional RP columns. The results indicate the overall usefulness of $\pi . . . \pi$ interactions, which can be utilised to reinforce the retention of these highly polar compounds. Very good resolution of 1-propyl-3-methylimidazolium and 1-ethyl-3-ethylimidazolium salts (identical in lipophilicity) was obtained. It was also observed, however, that low-molecular ionic liquid cations yielded very misshapen peaks. Early peak tailing can be attributed to energetic surface heterogeneity with overloading of highly energetic adsorption sites, among other things. It is likely that low-molecular ionic liquids are retained at these sites as a result of the predominant ion-exchange type of interactions. This can further lead to slower sorption - desorption kinetics of solutes from strong sites than from weak ones, which consequently exacerbates band tailing. In more hydrophobic ionic liquids, this effect was not so evident, showing that the predominant interaction mechanism is due to partition and $\pi$... $\pi$ interaction. Furthermore, to differentiate between hydrophobic and aromatic interactions, methanol and acetonitrile were compared as organic modifiers of the mobile phases. Unlike methanol, acetonitrile is an electron-rich modifier and can suppress the $\pi . . . \pi$ interaction. As expected, when the acetonitrile concentration was increased, ionic liquid-stationary phase interactions weakened much faster in comparison to the changes due to the methanol-modified mobile phase. Moreover, the applied chromatographic conditions were optimised for analytical performance parameters. Excellent calibration curve linearity was obtained for the compounds analysed. The linear correlation coefficients ranged from 0.9992 to 0.9995 over a wide concentration range (10 to $1000 \mu \mathrm{M})$. The retention time RSDs ranged from 0.11 to $0.25 \%$, and the peak area RSDs also lay in good ranges, from 0.35 to $2.27 \%$. The lowest detection limit of $1 \mu \mathrm{M}$ was obtained for the 1-benzyl-3-methylimidazolium cation. Additionally, the separation of 1-butyl-3-methylimidazolium chloride and its degradation products obtained in the Fenton degradation system demonstrated that the method is readily applicable to the various experiments tracking the cationic constituents of ionic liquids in aqueous solutions.

\subsection{Chromatography of specific surface structural properties}

One recent study investigated different types of columns with specific structural properties [26]. Packings containing cholesterol ligands chemically bonded to silica (SG-CHOL), and mixed stationary phases (SG-MIX) containing cyanopropyl, aminopropyl, phenyl and octadecyl ligands were tested. There were significant differences in the results: packings containing functional groups bonded to the silica surface and capable of undergoing protonisation turned out to be unsuitable for separating ionic liquids under the given analytical conditions (methanol : $40 \mathrm{mM}$ potassium phosphate buffer, $\mathrm{pH}=4$ ). In this comparison, the butyl and octadecyl stationary phases yielded the best results (RP-18e Innovation Chromolith ${ }^{\mathrm{TM}}$ performance and Macrosphere $300 \mathrm{C} 4$ packings respectively). This was most probably due to the lowest heterogeneity of these ligands in comparison to the other phases tested. It 
seems that stationary phases with specific structural properties, for example, with cholesterol and mixed ligands, are unsuitable for separating ionic liquid cation mixtures.

In another paper, the use of column packing with an immobilised artificial membrane IAM moiety is reported [27]. In this study, ionic liquids were separated in order to determine their lipophilicity, since the IAM phase resembles the phospholipid bilayer. Four alkylimidazolium ionic liquids (from $\mathrm{C}_{3}$ to $\mathrm{C}_{6}$ ) were analysed under isocratic conditions using a mobile phase consisting of phosphate buffer at $\mathrm{pH} 6.5$ and methanol in varying proportions from 10-50\%. The capacity factors obtained for different quantities of methanol were extrapolated to $0 \%$ methanol and described as the relative lipophilicity $\left(\log k_{w}\right)$ using a linear procedure. The retention-derived lipophilicities determined on an immobilised artificial membrane were substantially higher than those obtained with reversed phase chromatography or those obtained from equilibration experiments in the 1-octanol/water system [28-29]. Estimated log $k_{w}$ values ranged from 0.92 to 1.7 , and the corresponding $\mathrm{R}^{2}$ of the capacity factor extrapolations were satisfactory. The retention times, and hence the capacity factors, were the net result of several interactions occurring during partitioning to this phase. Not only did hydrophobic partitioning occur here; interactions of positively charged nitrogen with the carbonyl and phosphate groups present in the IAM stationary phase closely mimicking the surface of a biological membrane also occurred. This is a very important result, which suggests that ionic liquids, hitherto regarded as highly polar entities, can also interact with biological membranes.

\subsection{Sample pre-treatment}

Sample pre-treatment is commonly required in quantitative assays for trace amounts of analytes in environmental or biological samples. Pre-concentration not only increases the method's sensitivity; it also eliminates interfering compounds. Recently, a selective method was tested for cleaning up and pre-concentrating ionic liquid cations from environmental water samples using cation-exchange solid phase extraction followed by selective elution [30]. The best recoveries (over 95\%) for all the compounds examined with this method were obtained with a methanol solution in saturated ammonium chloride adjusted with $\mathrm{H}_{3} \mathrm{PO}_{4}$ to $\mathrm{pH}$ 3. Also, three sample matrices were chosen to demonstrate the method's applicability: tap water, seawater and freshwater. In the case of tap water, all the compounds except the AMIM cation are recovered with an excellent yield above $90 \%$. The best recoveries are found for ionic liquids containing the largest functionalities in position $\mathrm{N}-1$, namely the 1-hexyl- and 1-p-methylbenzyl-3-methylimidazolium entities. As with the tap water, extraction of the freshwater samples spiked with ionic liquids gave satisfactory results as well. All the compounds were recovered at a comparable level (mean recovery $96.1 \pm 3.6 \%$ ), regardless of structural differences. The lowest recovery rates were recorded for ionic liquids extracted from the seawater samples, but enrichment of the imidazolium compounds is still at a satisfactory level (>90\%). The lower recoveries are obviously due to the higher ionic strength of the seawater, which may interfere with the numerous other cations probably sorbed in the cartridge. Pre-concentration of environmental samples showed that the suggested method could be applied to the analysis of 1-alkyl- and 1-aryl-3-methylimidazolium cations in environmental waters with very good recovery yields. 


\section{Electrophoretic methods}

The first study employing capillary zone electrophoresis in the analysis of ionic liquids was employed for separating and detecting 1-alkyl-3-methylimidazolium entities, including isomers and related imidazole derivatives [31]. The running buffer consisted of $5.0 \mathrm{mM}$ triethylamine in acidic conditions, because the mobility of the triethylammonium co-ion formed resembles that of the analytes under study, thus governing the good symmetry of the peaks obtained. Additionally, $2.0 \mathrm{mM}$ of $\alpha$ cyclodextrin was added to the running buffer in order to achieve separation of two isomers - [iBMIM $]^{+}$ and $[\mathrm{BMIM}]^{+}$. Under these conditions all compounds (ionic and neutral) were baseline-separated inside $8 \mathrm{~min}$, with detection limits ranging from 0.4 to $1.4 \mathrm{ppm}$. With this method, impurities could be detected in commercial ionic liquids and a process analysis during the synthesis of [BMIM][Cl] ionic liquid could be carried out.

Capillary electrophoresis was also employed in a recent study for resolving selected imidazolium ionic liquid cations in standard mixtures [32]. The results showed that both the method's sensitivity and its resolution reached a maximum when sodium citrate buffer was used as background electrolyte. The separation of a standard mixture is in linear accordance with the molecular weight, hence the theoretical prediction of compounds not yet analysed is possible; however, cations with identical molecular masses are inseparable with this method. In spite of this, the method's quantitative analytical performance was excellent. RSD migration times ranged from 0.05 to $0.1 \%$. The detection limit of the 1-ethyl-3-methylimidazolium cation obtained with a $500 \mathrm{~s}$ injection time was $0.01 \mu \mathrm{g} \mathrm{ml}^{-1}$. In order to validate the method's applicability, samples obtained during a photodegradation experiment of 1-butyl3-methylimidazolium tetrafluoroborate were tested. The target solute was well separated from its degradation product and was readily quantifiable.

\section{Conclusions}

Most of the methods for separating and determining ionic liquid cations reported on so far concern high performance liquid chromatography with a variety of columns and mobile phases. Two electrophoretic methods are also described, the results of which appear to be very promising, especially in the sensitivity area. In general, when buffered mobile systems are used, different anions do not affect the chromatographic behaviour of the same cation. But when buffer-free mobile phase systems are used, anions do influence the retention of the same ionic liquid cation owing to their additional interactions with the stationary phase. All the ionic liquids analysed exhibit reversed-phase behaviour while being separated. In RP systems selective separation of highly hydrophilic solutes is still a challenge, but using strong cation exchange chromatography permits this separation by appropriate modifications of the mobile phase. Moreover, the aromatic system in the imidazolium or pyridinium ring can be utilised to reinforce the retention of these highly polar compounds by the application of a polar RP phase containing a $\pi$-electron moiety. It is also possible to selectively pre-concentrate ionic liquid cations from highly dilute solutions by solid phase extraction, which in many cases is a prerequisite to the direct analysis of the compounds.

In the capillary electrophoretic methods reported so far, separations of co-eluting isomers were achieved by the addition of $\alpha$-cyclodextrin to the running buffer. In another CE method, in which citric 
buffer is used as the running electrolyte, the separation of a standard mixture is in linear accordance with the molecular weight, so the theoretical prediction of compounds as yet not analysed is possible. Most of the methods reviewed here report on the applicability of analytical protocols to real life samples, such as cell growing media, Fenton process degradation products or process analysis during the synthesis of ionic liquids.

\section{Acknowledgment}

Financial support was provided by the Polish Ministry of Research and Higher Education under grants: 2P04G 083 29, 2P04G 11829 and DS 8390-4-0141-6

\section{References and Notes}

1. Rogers, R.D.; Seddon, K. Ionic Liquids: Industrial Applications for Green Chemistry, American Chemical Society ACS Ser. 818, Oxford University Press, Washington DC, 2002.

2. Olivier-Bourbigou; H, Magna, L. Ionic liquids: Perspectives for organic and catalytic reactions. J. Mol. Catalysis A. 2002, 182, 419-437.

3. Wasserscheid, P.; Welton, T. Ionic Liquids in Synthesis, Wiley-VCH Verlag GmbH \& Co. KGaA, Weinheim, 2002

4. Holbrey, J.D.; Seddon, K.R. Ionic liquids, Clean Products and Processes, 1990, 1, 223-226

5. Huddleston, J.G.; Visser, A.G.; Reichert, W.M.; Willauer, H.D.; Broker G.A.; Rogers R.D. Characterization and comaprison of hydrophilic and hydrophobic room temperature ionic liquids incorporating the imidazolium cation, Green Chem., 2001, 3, 156-164

6. Papageorgiou, N.; Athanassov, Y.; Armand, M.; Bonhôte, P.; Pettersson, H.; Azam, A.; Grätzel, M. The performance and stability of ambient temperature molten salts for solar cell applications, $J$ Electrochem Soc, 1996, 143, 3099-3108

7. Armstrong, D.W.; He, L.; Liu, Y-S. Examination of ionic liquids and their interaction with molecules, when used as stationary phases in gas chromatography, Anal. Chem., 1999, 71, 38733876

8. He, L.; Zhang, W.; Zhao, L.; Liu, X.; Jiang, S. Effect of 1-alkyl-3-methylimidazolium-based ionic liquids as the eluent on the separation of ephedrines by liquid chromatography, J. Chromatogr. A, 2003, 1007, 39-45

9. Kaliszan, R.; Marszałł, M.P.; Markuszewski, M.J.; Bączek, T.; Pernak, J. Suppression of deletrious effects of free silanols in liquid chromatography by imidazolium tetrafluoroborate ionic liquids, $J$. Chromatogr. A, 2004, 1030, 263-271

10. Vaher, M.; Koel, M.; Kaljurand, M. Application of 1-alkyl-3-methylimidazolium-based ionic liquids in non-aqueous capillary electrophoresis J. Chromatogr. A, 2002, 979, 27-32

11. Majewski, P.; Pernak, A.; Grzymisławski, M.; Iwanik, K.; Pernak, J. Ionic liquids in embalming and tissue preservation. Can traditional formalin-fixation be replaced safely? Acta Histochem. 2003; 105(2), 135-42

12. Anastas, P.T.; Warner, J.C. Green Chemistry: Theory and Practice, Oxford University Press, 1998

13. Seddon, K.R.; Stark, A.; Torres M.J. Influence of chloride, water, and organic solvents on the physical properties of ionic liquids, Pure Appl. Chem., 2000, 72, 2275-2287 
14. Billard, I.; Moutiers, G.; Labet, A.; El Azzi, A.; Gaillard, C.; Mariet, C.; Lutzenkirchen, K. Stability of Divalent Europium in an Ionic Liquid: Spectroscopic Investigations in 1-Methyl-3butylimidazolium Hexafluorophosphate, Inorg. Chem., 2003, 42, 1726-1733

15. Park S.; Kazlauskas, R. J. Improved preparation and use of room temperature ionic liquids in lipase-catalyzed enantio- and regioselective acylations, J. Org. Chem., 2001, 66, 8395- 8401

16. Anderson, J. L.; Ding, J.; Welton, T.; Armstrong, D. W. Characterizing Ionic Liquids On the Basis of Multiple Solvation Interactions, J. Am. Chem. Soc., 2002, 124, 14247-14254

17. Villagran, C.; Deetlefs, M.; Pitner, W. R.; Hardacre, C. Quantification of halide in ionic liquids using ion chromatography Anal. Chem., 2004, 76, 2118- 2123

18. Berthier, D.; Varenne, A.; Gareil, P.; Digne, M.; Lienemann, C.-P.; Magna, L.; Olivier-Bourbigou, H. Capillary electrophoresis monitoring of halide impurities in ionic liquids, Analyst, 2004, 129, $1257-1261$

19. McCamley, K.; Warner, N. A.; Lamoureux, M. M.; Scammells, P. J.; Singer, R.D. Quantification of chloride ion impurities in ionic liquids using ICP-MS analysis, Green Chem., 2004, 7,341-344

20. Stepnowski, P.; Müller, A.; Behrend, P.; Ranke, J.; Hoffmann, J.; Jastorff, B. Reversed-phase liquid chromatography of selected room-temperature ionic cations, J. Chrom. A, 2003, 993, 173-178

21. Stepnowski, P.; Mrozik, W. Analysis of selected ionic liquid cations by ion exchange chromatography and reversed-phase high performance liquid chromatography. J. Sep. Sci., 2005, 28, 149-154

22. Ruiz-Angel, M. J.; Berthod, A.; Reversed phase liquid chromatography of alkyl-imidazolium ionic liquids, J. Chromatogr. A, 2006, 1113, (1-2), 101-108

23. Berthod, A.; Ruiz-Angel, M.J.; Huguet, S. Nonmolecular Solvents in Separation Methods: Dual Nature of Room Temperature Ionic Liquids, Anal. Chem., 2005, 77, 4071-4080

24. Stuff, J. R. Separation of cations in buffered 1-methyl-3-ethylimidazolium chloride-aluminum chloride ionic liquids by ion chromatography J. Chromatogr., 1991, 547, 484-487.

25. Stepnowski, P.; Nichthauser, J.; Mrozik, W.; Buszewski, B. Usefulness of $\pi . . \pi$ aromatic interactions in the selective separation and analysis of imidazolium and pyridinium ionic liquid cations, Anal. Bioanal. Chem. 2006, 385, 1483-1491.

26. Kowalska, S.; Buszewski, B.; Stepnowski, P. The influence of stationary phase properties on ionic liquid cations separation in RP-HPLC. J. Sep. Sci. 2006, 29, 1116 - 1125

27. Stepnowski, P.; Storoniak, P. Lipophilicity and metabolic route prediction of imidazolium ionic liquids, Environ. Sci. Poll. Res., 2005, 12, 199-204

28. Domańska, U.; Bogel-Łukasik E.; Bogel-Łukasik, R. 1-Octanol/Water Partition Coefficients of 1Alkyl-3-methylimidazolium ChlorideChem. Eur. J., 2003, 9, 3033-3041

29. Ropel, L.; Belveze, L.S.; Aki, S.N.V.K.; Stadtherr M.A.; Brennecke, J.F. Octanol-water partition coefcicients of imidazolium-based ionic liquids Green Chem., 2005, 7, 83-90

30. Stepnowski, P. Solid phase extraction of ionic liquids from environmental aqueous samples, Anal. Bioanal. Chem., 2005, 381 (1), 189-193

31. Qin, W.; Wei, H.; Li, F.Y. Separation of ionic liquid cations and related imidazole derivatives by acyclodextrin modified capillary zone electrophoresis, Analyst, 2002, 127, 490-493 
32. Markuszewski, M.J.; Stepnowski, P.; Marszałł, M.P. Capillary electrophoretic separation of cationic constituents of imidazolium ionic liquids, Electrophoresis, 2004, 25, 3450-3454

33. Suarez, P.A.Z.; Einloft, S.; Dullius, J.E.L.; de Souza, R.F.; Dupont, J. Synthesis and physicalchemical properties of ionic liquids based on 1- n-butyl-3-methylimidazolium cation, J. Chim. Phys. Phys. Chim. Biol., 1998, 95, 1626-1639

34. Seddon, K.R.; Stark, A.; Torres, M.J. Influence of chloride, water, and organic solvents on the physical properties of ionic liquids. Pure Appl. Chem., 2000, 72, 2275 - 2287.

35. Visser, A.E.; Holbrey, J.R.; Rogers, R.D. Hydrophobic ionic liquids incorporating $N$ alkylisoquinolinium cations and their utilization in liquid/liquid separations. Chem. Commun., 2001 $2484-2485$.

36. Abraham, M.A.; Moens, L. Clean Solvents. Alternative media for chemical reactions and processing, ACS, Washington DC, 2002.

(C) 2006 by MDPI (http://www.mdpi.org). Reproduction is permitted for noncommercial purposes. 